\title{
Exploring the Relationship Between Food Insecurity, Gender Roles and HIV/AIDS Among Tonga Carers of Disabled Children of Binga in Zimbabwe
}

\author{
Jennifer Muderedzi ${ }^{1}$ D $\cdot$ Arne H. $^{-E_{i d e}}{ }^{(D)} \cdot$ Stine H. Braathen $^{2}$ (D) \\ Babill Stray-Pedersen ${ }^{1,3}$
}

Published online: 11 June 2019

(c) The Author(s) 2019

\begin{abstract}
Many people are reluctant to access voluntary counselling and testing services for fear of stigma and the implications of death often associated with a positive HIV diagnosis. This study however noted how Tonga females residing in Binga, one of Zimbabwe's poorest and most food insecure districts, were eager for an HIV positive result in order to secure food handouts from Non-Governmental Organisations. Using a conceptual framework developed by Weiser and colleagues for understanding the bidirectional links between food insecurity and HIV/AIDS linkages, this paper explored the relationship between food insecurity, gender roles and HIV/ AIDS. Qualitative in-depth interviews, participant observation and focus group discussions were conducted with 53 caregivers and four healthcare personnel. Data were analysed using content analysis. The findings show the interrelationship between food insecurity, gender roles and HIV/AIDS entwined in a vicious cycle that heightens vulnerability to and worsens the severity of each condition. The findings from this study can help in informing policy interventions geared towards HIV/ AIDS, gender inequality and food insecurity.
\end{abstract}

Keywords Tonga $\cdot$ HIV/AIDS $\cdot$ Gender roles $\cdot$ Food insecurity $\cdot$ Disability

Jennifer Muderedzi

jmuderedzi@gmail.com

Arne H. Eide

Arne.H.Eide@sintef.no

Stine H. Braathen

Stine.H.Braathen@sintef.no

Babill Stray-Pedersen

babill.stray-pedersen@medisin.uio.no

1 Institute of Clinical Medicine, University of Oslo, Box 1072, Blindern, 0316 Oslo, Norway

2 SINTEF - Sintef Digital, Department of Health, P.B. 124, Blindern, 0314 Oslo, Norway

3 Division of Women, Rikshospitalet, Oslo: Oslo University Hospital, Oslo, Norway 


\section{Introduction}

Food insecurity and HIV/AIDS remain global, social and public health challenges (Masa and Chowa 2017). The reciprocal relationship between food insecurity and HIV/AIDS has been well documented as a leading cause of morbidity and mortality in many settings in Sub-Saharan Africa (Weiser et al. 2015; Vogenthaler et al. 2013; Tsai et al. 2011). Despite this, mechanisms through which food insecurity can lead to HIV are less explored (Weiser et al. 2011). Research has found that improvements in household food security and nutrition are associated with women's access to income and their role in household decisions on expenditure as women tend to spend a significantly higher proportion of their income than men on food for the family (Hyder et al. 2005). Despite women being the key figures in agriculture and food security, gender inequality is holding back progress towards ending hunger, poverty and creating sustainable food systems (FAO et al. 2018). Thus, empowering women has the potential to bring major gains to society at large, because it can increase production, improve food security and nutrition, boost the economy and improve human capital of future generations, thereby fostering long-term economic growth (Saunyama 2017).

Food insecurity is the limited or uncertain availability of nutritionally adequate, safe foods, or the inability to acquire personally acceptable food in socially acceptable ways (Fawole et al. 2015; Frimpong 2013; Anema et al. 2009). The definition incorporates overlapping challenges, including insufficient quantity, poor quality, limited diversity, or compromised safety of food; inadequate access of food, leading to hunger and anxiety; and the need for socially unacceptable procurement of food, including begging, relying on charity, exchanging sex for food, stealing food, and other activities (Anema et al. 2009).

There is more than enough food in the world to feed everyone yet estimates indicate that between 2012 and 2014 at least 805 million people experienced extreme chronic malnourishment, $60 \%$ being women and girls (FAO et al. 2014). Worldwide, and in Africa in particular, women traditionally play a critical role in securing food for their families despite major constraints to meet basic family survival needs. Evidence shows a strong correlation between gender inequality and food nutrition insecurity (FAO et al. 2014). Women's own food security and nutrition needs - and often those of their daughters, are being neglected at the household level, where discriminatory social and cultural norms prevail (Brody 2015). Gender inequality both leads to and is a result of food insecurity that increases the risk of HIV through risky coping strategies and on the other hand, HIV heightens vulnerability to food insecurity by limiting household income and food production (Kadiyala and Rawat 2013; Weiser et al. 2011).

Food insecurity is hypothesized to increase sexual vulnerability, especially among women living in poverty and who are often dependent on others for food and other resources, and whose human rights are inadequately protected (Miller et al. 2011). Women have historically been largely landless, most owning little or no land themselves resulting in a gender gap in access to land (Agarwal 2012). Weaver and Hadley (2009) found a strong association between food insecurity and 


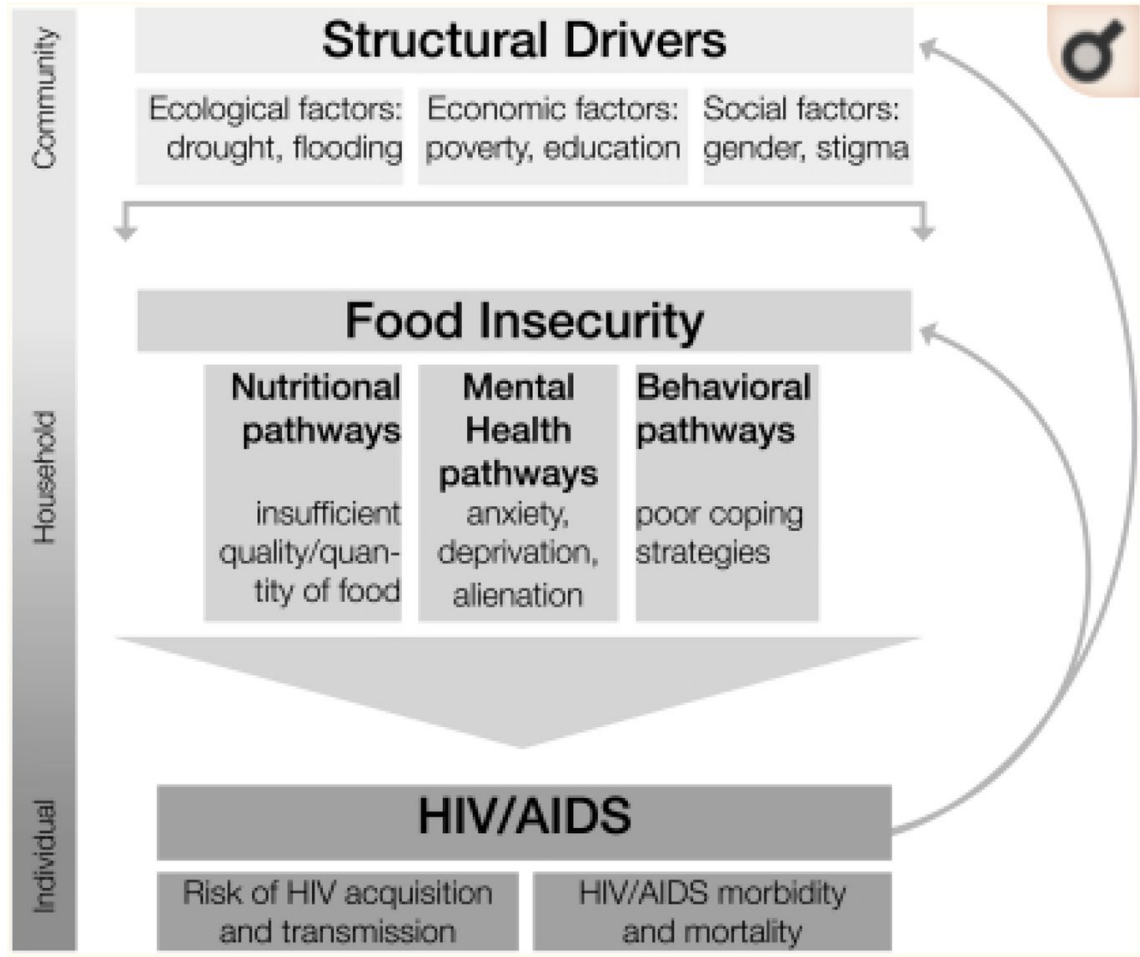

Fig. 1 Conceptual framework for understanding the bidirectional links between food insecurity and HIV/ AIDS. The figure was provided by Dr. Sheri Weiser

increased mental illness symptoms such as anxiety and depression among mothers with children in food insufficient situations. These inequalities result from a variety of causes, including low level of female autonomy, unequal control of resources and household food allocation (Weiser et al. 2015; Susser 2009). Thus, food insecurity and HIV/AIDS are highly gendered phenomena that needs to be explored in order to get an in-depth understanding of the interrelationship. Data is from an ethnographic study undertaken among the Tonga of Binga in Zimbabwe.

In Fig. 1, the Weiser et al. (2011) conceptual framework shows how food insecurity and HIV/AIDS are intertwined in a cycle through nutritional, mental health, and behavioural pathways. The framework spans three levels of determinants; community, household and individual. Broader structural factors influence food insecurity at the community level. These include climatic features (e.g. drought, flooding), socio-economic factors (e.g. poverty, access to education), social factors (e.g. gender equality, health related stigma) and local food availability. Food insecurity typically operates at the level of the household, and is influenced by other household factors, such as family structure and social support. Specifically, food insecurity can lead to macro-nutrient and micronutrient deficiencies, which can affect the transmission of HIV, and can also contribute to immunologic decline and increased morbidity and 
mortality among those already infected (Weiser et al. 2011). Food insecurity in turn shapes individual behaviours and HIV/AIDS outcomes through nutritional, mental health and behavioural pathways. The framework also portrays the reciprocal relationship between food insecurity and HIV/AIDS acquisition and transmission.

\section{Food Insecurity and HIV/AIDS in Binga}

The food security situation in Zimbabwe is positioned as part of a larger economic decline with low agricultural productivity, deteriorating standards of living, government corruption and policy inconsistencies (ZCAWD 2014). As a result, most households in rural areas buy food, because they cannot produce enough to meet their daily needs (Ncube 2016). Such a situation exacerbates food insecurity and the HIV epidemic, which are inextricably linked and perpetuate each other. About $80 \%$ of Tonga people residing in Binga suffer from high levels of poverty and most households face chronic food shortages that threaten their everyday lives (Rural Poverty Portal 2015; Mudimba 2015; Cumanzala and Muleya 2010). Politics also plays a huge part of food inefficiency as the government is known to withhold food aid from the Tonga communities (Muderedzi et al. 2017).

The Tonga situation is not only about limited food access but a complex context in which malnutrition feeds a vicious cycle made of poor diet and lack of incomes to diversify the diet. Average annual yields per household range from two to three bags of millet on the allocated five acres of arable land, which is far from being sufficient for domestic consumption (Agriculture Extension 2004; Mwaramba et al. 2001). Despite external food aid, the communities remain vulnerable to drought and poor soils. Out of the ten provinces in Zimbabwe, Matabeleland North where Binga is situated has the second highest HIV prevalence for adults at $17.6 \%$ and the highest among children under 14 years old at 3.2\% (ZDHS 2016; Zimphia 2016).

\section{Gender Roles, Food Insecurity and HIV/AIDS}

Culture includes everything that is learnt in a society. It is a transfer from collective to the individual and is not static, but in constant flux (Ncube 2016; Haralambos and Holborn 2008). Cultural traditions and social structures across the developing world often lead to women being more affected by hunger and poverty than men, even though women, particularly expectant and nursing mothers, often need special or increased intake of food (FAO 2011). Women are more vulnerable due to their lack of access to and control over resources including land, employment and money (UN DESA 2015; Miller et al. 2011). As a result of the inability to procure food, in socially or personally acceptable ways, food insecurity also contributes to risky sexual practices and enhanced HIV transmission (Weiser et al. 2011, 2012; Miller et al. 2011).

In many parts of Africa, men and women make unequal use of public health facilities with women having more contact with health facilities mainly through reproductive and child health services. As a result of this gender disparity in health care, men have fewer opportunities and disproportionately poorer access to HIV testing, prevention, care and treatment services (van Rooyen et al. 2013). The fear 
of knowing one's HIV status has been shown to originate from perceiving an HIV positive result as a death sentence and from the anticipation of severe stigma (Jurgensen et al. 2012; De Wit and Adam 2008). However, women attending ante-natal clinics (ANC) are more inclined to get tested due to their concern for the health of the expected baby, self-perceived HIV risk, and knowledge of medical intervention to reduce disease symptoms or prevent vertical transmission (Basilwizi Trust 2012; Cumanzala and Muleya 2010). Various studies in Sub-Sahara Africa have reported men shunning HIV testing for different reasons such as gender norms and ideas of hegemonic masculinity where toughness and self-reliance are valued (Van Rooyen et al. 2013; O'Brien et al. 2005). This can be seen as culture creating male vulnerability to HIV/AIDS.

\section{Aim of Research}

This paper utilizes the Weiser framework on food insecurity and HIV/AIDS to explore the mechanisms by which food insecurity, gender roles and HIV/AIDS are linked at community, household and individual levels. The aim is to generate knowledge that can contribute to develop effective interventions to reduce food insecurity, address gender-based inequities and reduce HIV/AIDS acquisition and transmission, depending on our understanding of these multifaceted relationships.

\section{Study Context}

Binga district in Matabeleland North province is situated in the northwest of Zimbabwe with the Zambian border. The district consists of twenty-one wards with a total population of 139,092 (Zimbabwe Population Census 2012). It is geographically, socially and politically marginalised within Zimbabwe (Mudimba 2015; Munsaka and Charnley 2013; Cumanzala and Muleya 2010). Minimal healthcare, education and development to the district persist (Mudimba 2015; Mashingaidze 2013). For more details of the history of Tonga vulnerability and forced displacements from the Zambezi valley, see Muderedzi et al. (2017).

For HIV/AIDS services, the whole district relies on one Opportunistic Infection (OI) clinic at the district hospital. The primary clinics collect Anti-retroviral (ARV) medications from the OI clinic, when available. Adding to this, a few NonGovernmental Organisations (NGOs), such as the Zimbabwe Association of Church Hospitals (ZACH), assist the communities with Voluntary Counselling and Testing (VCT), ARVs and food aid. Unfortunately these services cannot be accessed by communities in remote areas due to lack of road infrastructure. This situation can be attributed to government discriminatory policies, such as withholding food aid during election times, and general lack of development to the district (Munsaka and Charnley 2013; Currey 2009; Tremmel et al. 1994).

The Tonga are known to guard their culture and traditions which they still practice today (Cumanzala and Muleya 2010; Currey 2009; Tremmel et al. 1994). A combination of the patriarchal system, Tonga matrilineal lineage and clan along with polygynous marriage systems are seen as assets that facilitate broad social 
networks and flexible systems of resource access, helping people meet material needs (Mudimba 2015; Haller and Merten 2013). However, those same systems can foster conditions in which people may be at increased risk for HIV and particular kinds of social inequalities and often placing men in privileged roles (Ncube 2016; Malungo 2010). Tonga cultural practices, traditional beliefs and customs continue to greatly influence the organisation and functioning of Tonga communities today and most have had minimal influence by modernization (Ncube 2016; Munsaka 2012).

\section{Methodology}

This paper emanates from a larger study on vulnerability, disability and structural violence among the Tonga of Binga in Zimbabwe (Muderedzi et al. 2018). Informants were purposively sampled because they possessed characteristics in which we were interested (Silverman 2013). In this case, this was Tonga informants with disabled children (birth-13 years) residing in Binga. While the main focus of the larger study was on how society deals with disability, the centrality of HIV/AIDS issues in particular for women, emerged during data collection. Respondents for this paper consisted of 53 caregivers (33 females and 20 males) and four healthcare professionals (two males and two females) from the OI clinic at the district hospital.

The study used a triangulation of qualitative data collection methods namely 53 in-depth interviews, participant observation in 20 households and 10 focus group discussions, as well as notes and secondary data (documents). In-depth interviews were conducted in the language ChiTonga (the mother tongue of all informants), took place at informants' homesteads and lasted for approximately an hour. In-depth interviews were chosen due to their non-standardised, open-ended and in-depth approach. Open-ended questions allowed participants to include more information such as feelings, attitudes and their understanding of HIV/AIDS. Participant observations were of 3 days duration at each homestead whereby the researchers stayed with the family and were involved in activities of daily living (ADL), including community activities. Focus group discussions were also used to verify data authenticity after data analysis to ensure the reliability of the identified themes after back translation from English to ChiTonga. Field notes and secondary data (documents) were incorporated to add more clarity and validity to the data collection techniques. Data saturation was reached. Four in-depth interviews and one focus group discussion yielded data from the health professionals.

The researcher, who is Zimbabwean had a fairly good command of chiTonga and the research assistant was a Tonga rehabilitation technician and researcher with over 30 years of experience working at the district hospital's rehabilitation department and in the community.

Data were transcribed verbatim and translated into English. The data were labelled through open coding, using conceptual categories to develop the codes (Silverman 2013). The codes were derived both from the literature and the actual data (Corbin and Strauss 2008). Transcripts were read several times and factors that were associated with food insecurity, gender inequality and HIV/AIDS were identified. 


\section{Ethics}

Ethical approval was obtained from the Medical Research Council of Zimbabwe (MRCZ_Ref. MRCZ/B/286) and the Regional Medical ethics committee (REKcase 2015/397) in Norway. The aim of the study was explained to the informants who gave their consent by signing a consent form or putting an ' $X$ ' as signature. Informants were identified by numbers so that anonymity and confidentiality was maintained. A thank you token of USD 5 was given to each family after in-depth interviews. Informants who took part in participant observation received USD 10 worth of groceries as they hosted the researchers for 3 days. The researchers provided child care information and handling techniques. Disabled children were shown how to carry out activities of daily living techniques such as washing, dressing, feeding and mobility. Referrals to specialists or provincial hospitals were not feasible due to informants' economic hardships.

\section{Results}

The themes that emerged from the data analysis were (a) informants' awareness and risk of contracting HIV, (b) the relationship between HIV/AIDS and food insecurity (c), gender roles and culture. The relationship between the Weiser et al. framework (2011) and our data analysis is that the structural drivers such as ecological, economic, social and political factors were manifested in food insecurity, which in turn resulted in HIV/AIDS acquisition and transmission. These links can be reversed, e.g. HIV/AIDS or disability in an adult can cause food insecurity in a household in the sense that household labour is reduced, which in turn has economic and social consequences. Furthermore, the three themes bring out a strong gender factor in the exploration of the interrelationship of food insecurity and HIV/AIDS.

\section{Awareness and Perceived Risk of Contracting HIV}

Both male and female informants were aware of HIV/AIDS. However, during focus group discussions, it was noted that more women than men (3:1) had taken the HIV test through VCT services or the district hospital. Several NGOs in the area provide food aid to people who are HIV positive. As a result, many of the women had taken numerous tests in anticipation of an HIV positive result in order to receive food aid so as to feed their families. Consequently, women were more knowledgeable about causes and risks of HIV/AIDS than their male counterparts since they received information from these places.

More than half of the males who had tested had not collected their results, stating that they would do so later. Some male informants living in remote mountain areas where VCT services were not available reported not being at risk since they were far away from villages that were active in occupations such as fishing and travelling to and from the nearest towns of Hwange or Victoria Falls. They cited fishing communities as highly susceptible to HIV due to factors such as fishermen staying away 
from home for longer periods without their wives, engaging with fish traders from other areas, have access to cash income and a ready availability of commercial sex.

The fishing industry in the area attracts many fish traders from outside the district resulting in a lively 'sex for fish' trade (prostitution) in the fishing camps such as Siachilaba and Binga. Such communities have been identified as among the highest risk groups for HIV infection.

Despite being aware of this risk, one female informant stated;

I am aware of the disease but our families need food so we go to the fisheries to buy fish

(28 year old female)

A large part of the district is unreachable due to lack of road infrastructure, wild animal attacks, extreme high temperatures and remote mountain areas. Consequently, these communities were not receiving VCT activities, resulting in lack of knowledge and HIV testing.

This lack of knowledge is reflected in the statements by informants below:

My wife and child died but I do not know if it is really the HIV. It could be witchcraft (30 year old male)

There is no risk for us. Where will the disease come from? You say it comes from outside-where? My wives do not go to the fisheries or Hwange where there is prostitution ( 45 year old male)

The communities in and around the district hospital as well as around health centres had access to HIV/AIDS and general reproductive health information from different additional sources such as NGOs, AIDS service organisations, peer educators and the media. As a result, in study areas located near health facilities, informants displayed better knowledge and understanding of HIV/AIDS. Most of the study areas, however, were located further away from health facilities, and informants in these areas displayed lower levels of knowledge and awareness. Having been exposed to HIV, for instance through the illness or death of someone close to them, also seemed to increase people's awareness of the disease. One male informant stated;

Yes. I am aware of the epidemic and that one can contract the disease. My two brothers, three children and one of my wives died from the disease (62 year old male)

\section{HIV/AIDS and Food Security}

In Zimbabwe the routine for food aid linked to HIV positive individuals takes place among food insecure communities who cannot access ARVs and is administered by NGOs. Individuals are supposed to go through the VCT process and only those who test HIV positive and are put on treatment receive food aid. In Binga, ZACH was one of the main organisations offering these services. Due to lack of road infrastructure development, many parts of the district were unreachable, cutting off these 
communities from this and many other aid services. This resulted in a large number of women walking for miles to access VCT services citing lack of the staple food of maize/sorghum and surviving on wild leaf okra without the starch.

In focus group discussions, several men said that 'banakazi batesitilwa kulya' meaning that 'women get tested in order to get food'. The women did not dispute that stating that they had the duty to feed their families.

When asked why they were not afraid of getting tested, the female informants explained that if they had enough food to feed the family, they may be reluctant to get tested. However, most of them struggled to find enough food, and testing HIV positive would provide them with an opportunity for receiving food aid. One 40 year old female, for instance stated;

Fear to be tested is when you have food to feed the children at home.

Adding to this, to the women, HIV was said to be 'one of those things that happen in life. It is not a crisis'. Many women walked distances of forty kilometres or more to and from their homes to the VCT meeting points or the district hospital to get tested for HIV. When asked why they were so eager to be tested, they stated that 'Ndatestwa ndiyanda kubona bumi bwangu' translated to: 'I want to get tested so as to know my status'. HIV was seen as more or less the same as hypertension or diabetes mellitus; a chronic illness that needed medication to survive. The women pointed to their swollen feet and ankles stating that they needed to get tested in case they were positive, and then they would get food aid and treatment. On further probing, they stated that if they receive a negative result, they return after a few months for another test. One 28 year old female stated;

I have been tested three times now. First by the VCT people and twice at the hospital when I brought my sick child to be treated.

This was also confirmed by the nurses at the district hospital (OI clinic) who noted how the women would ask for testing numerous times especially when they brought their sick relatives to the hospital. One nurse stated;

We do not refuse to test the women who ask to be tested several times since it is our job to test anyone who asks for the test.

When asked whether service users received enough counselling, the nurses stated that counselling was given to all the clients who attended the clinic, but hunger among the villagers made them return for more testing in anticipation of a positive result.

Stories of women asking their husbands to be unfaithful to bring home the virus were occasionally told to the researchers during women only activities, such as fetching water or firewood. This was also confirmed by the females during focus group discussions. The researchers witnessed women breaking down crying after receiving a negative result and stating, 'There is no food at home. What will I feed my children with?' Old ladies were seen to be begging VCT personnel to be registered as positive to access food aid for themselves as well as the grandchildren they 
were looking after stating, 'I am the only one in the village who is not getting food aid'.

\section{Gender Roles}

Tonga cultural factors were highly rated in the spread of HIV/AIDS. Polygyny, marriages between young girls and elderly men as well as widow inheritance are widely practiced. Women and girls are marginalized, hence early pregnancies and prostitution are quite prevalent. Widow inheritance and sexual cleansing are customs where a widow is inherited by her in-laws after she has sex with one of her deceased husband's male relatives. The ritual is said to free the widow from her husband's ghost, and if not done, the widow can go mad or die.

The factor most commonly associated with the spread of HIV/AIDS was inheritance of deceased relatives' wife or wives together with sexual cleansing of widows. This was followed by polygamous marriages inclusive of forced marriages of young girls to older men. Extra marital affairs achieved the lowest rate. The health professionals reiterated the same cause and hierarchy as the informants but seemed to think that extra marital affairs were rampant coupled with promiscuity among young adults.

Polygyny, the practice of having several wives, is common among the Tonga. From the men's point of view this practice was said to give respect to the man and to ensure that he is always looked after properly.

Polygyny is Tonga culture. That is who we are. I have four wives and 15 children. I am well respected by the community (69 year old male)

We are following in our fathers' footsteps. It helps when one wife is ill or is away, one still has his conjugal rights. It is good to have many wives and children (22 year old male)

From the women's point of view, the practice of polygyny was said to provide them, their children and their clan with better security:

Many children get sick and die. So the clan can still survive when there are many wives (60 year old female)

Inherited widows indicated that they were happy to be able to stay at the homestead of their in-laws looking after their children instead of having to move back to their maiden villages. This was noted to be a common practice and appreciated by many. The reasons given by the women of why they were satisfied with this arrangement were;

It is good for the children to grow up with their siblings (30 year old female)

I do not want to be a burden on my brothers back in my village (40 year old female)

In ChiTonga, my brother-in-law is my husband (70 year old female)

A large number of female informants agreed to the practice of sexual cleansing of widows whilst a smaller group was not so sure. The smaller group consisted mainly 
of young females who stated that they were worried of contracting HIV since the men were not forthcoming as the females to get tested.

\section{Discussion}

The Tonga situation must be seen as a result of historically produced social conditions of poverty, subordination of women, structural violence and environmental factors. Theirs is a culture of poverty in which the individual is preoccupied with survival in the present and where any effective concern for the future is missing. Binga district falls into the very low food security label meaning food insecurity with reduced food intake, disrupted eating patterns and hunger. Poverty traps of natural resources such as land and water, bad governance in the form of lack of development to the district and cultural practices such as polygyny created a situation of absolute poverty that rendered them not able to generate income or possess the necessary resources to survive. Our findings show a clear interrelationship between food insecurity, gender roles and HIV/AIDS, entwined in a vicious cycle that heightened vulnerability to and worsened the severity of each condition.

Traditionally Tonga females were the ones that were fishing, owned the land and were responsible for growing crops. These aspects of their matrilineal culture changed when they were displaced by the construction of the Kariba dam, aspects that reduced their access to resources and food security. As a result, gender poverty and inequality were taking place in this patrilineal system where women's access to land was through their husbands who had permanent rights to land. Despite the fact that males had the right to land, lack of resources, insufficient rains, poor soils and wildlife resulted in extremely poor perennial harvests. Lack of economic power and livelihoods resulted in men not being able to produce or purchase food. Both Tonga men and women seemed to be unable to challenge the constraints in their daily lives. Labour was the only available factor of production that both sexes had but unfortunately for them, the absence of livelihoods and development to the district resulted in food and healthcare deficiency. As a result, food gathering had been totally left to the females as noted by the VCT attendances and men's statements that females access VCT for food aid. Gender inequality both led to and was a result of food insecurity.

Vulnerability describes the Tonga situation that threatened whole communities. This was noted by the coping strategies employed by families and individuals as well as their inability to plan for the future. The four dimensions of food security; access, availability, stability and utilization were missing in these communities. As a result, a situation of not knowing where one's next meal will come from was a cause of stress that affected mainly the women who had to adopt different coping strategies to obtain food to feed their families. Such a dire situation resulted in females resorting to sexual or non-sexual coping strategies in order to access food. For instance, teenage marriages largely forced on young girls to elderly men resulted in health issues such as increased risk of sexually transmitted diseases, HIV/AIDS, death during childbirth as well as risks of premature birth and death of offspring. Many of these young females knew about these health issues from siblings, friends 
and neighbours' experiences but the need for food was a priority for them and their families. Similar sentiments were stated by older females on the issue of polygyny and widow inheritance, factors that were in one way sustainable while at the same time providing a risky environment for HIV transmission. They reiterated that HIV came with food meaning that being HIV positive was not as important as the need for food. Women's lack of economic power and livelihoods as well as cultural practices impinged on their rights, responsibilities, opportunities and access to and control over resources.

In their case, access to resources was critical for their survival. The fact that most of them had malnourished under-five-years-old children suffering from diarrhoea, skin diseases, fever and needing healthcare, drove females to adopt poor coping strategies. Persistent malnutrition left particularly disabled children weak, resulting in delayed development milestones, stunting, cognitive problems and emaciation amongst other problems. Children were noted to be vulnerable and less able to fight common childhood diseases such as diarrhoea, respiratory infections, malaria, measles, and consequently death. This could have resulted in a precarious situation that exacerbated the high infant mortality and morbidity situation among these communities. Reports of high infant mortality and morbidity from village health workers, as well as the highest child HIV prevalence in Zimbabwe could be a result of such a situation. School going children were also not spared the harsh realities of food insecurity that included withdrawal from school or participation in fetching forest foods. In some cases such activities resulted in disabilities sustained from tree falls, snakebites or marauding wild animals. Insufficient quantities of food also subjected the families to resort to unorthodox foods such as boiled ashes with reports of feelings of anxiety and shame. Such a situation shaped individual actions and health outcomes through nutritional, mental health and behavioural pathways.

The study shows gender roles as one of the social determinants affecting food insecurity and HIV/AIDS. Gender roles posed obstacles to women's economic development resulting in a situation of gender inequality, insufficient food and the acquisition of HIV/AIDS. Therefore, an understanding of the complex linkages of HIV/AIDS, gender roles and food insecurity is critical for the integration of food and health programmes as well as safe cultural practices. Equity in access to resources by women to produce food and purchasing power to buy food where it is not produced will enhance their potential to generate food security.

Although both men and women experienced poverty, women were noted to be poorer than men, making the issue of poverty and gender inequality a social and economic problem that demands attention. What was needed was simply nutritious food and adequate health services for all, hence the pursuance of multiple HIV tests for food aid as well as cultural practices that put them at risk of HIV/AIDS. According to the adults, HIV/AIDS was not a crisis but 'one of those things that happen in life'; a situation which they could cope with since it was coming with treatment. Such an attitude could result in a caretaker's acquisition and transmission of HIV/ AIDS resulting in a negative household food security situation affecting food production and preparation due to illness, disability or death.

The vicious cycle of food insecurity, gender roles and HIV/AIDS needs to be broken for it affects people for a lifetime. This is evident in the case of young orphans 
who are growing up without parents, the acquisition of HIV/AIDS, forced unhappy marriages, child and adult temporary/permanent disabilities as well as a high mortality among the communities. Poverty, dependence on others for food security and resources as well as unprotected human rights all need social justice at the individual, household and community levels. In the case of the Tonga, it is important to know who is affected, why and how in order to devise ways to lessen the vulnerability of these communities, families and individuals, especially the autonomy of women which has been credited with containing the spread of HIV.

\section{Strengths and Weaknesses of the Study}

Measures to avoid bias were taken in the form of participants' reviewing the results and data verification with other data sources such as Tonga HIV/AIDS research projects by (Ncube 2016; Basilwizi Trust 2012; Cumanzala and Muleya 2010). The study was not intended to be representative for the entire Binga district. However, the theoretical backing through utilizing the Weiser et al. (2011) framework may have produced rather robust results that have relevance to the entire Tonga community. For further research in this field, representative data is called for. A comparative study would have highlighted disability specific challenges, as well as challenges that are more common across the population.

\section{Conclusion}

The understanding of the complex linkages between food insecurity, gender roles and HIV/AIDS can help in government policy interventions towards HIV/AIDS and in addressing the role of gender inequalities and food insecurity. There is need to address broader gender based inequities that force females to engage in risky behaviours due to hunger. The government needs to prioritise short term food assistance as well as long-term development strategies. An adequate response to HIV/AIDS prevention and treatment is a must for the Tonga of Binga, considering the high prevalence of HIV/AIDS in the district. The issue of gender inequality and cultural practices as risk factors need to be tackled by both the government, Tonga gatekeepers, and other stakeholders such as researchers and various other institutions including the international community working among the Tonga communities. These cultural practices can be influenced in positive ways through sensitive approaches that promote participation, communication and dialogue (Sikwibele 2010; Jackson 2002). Safety nets such as social services at the individual, household and community levels must be put in place.

Open Access This article is distributed under the terms of the Creative Commons Attribution 4.0 International License (http://creativecommons.org/licenses/by/4.0/), which permits unrestricted use, distribution, and reproduction in any medium, provided you give appropriate credit to the original author(s) and the source, provide a link to the Creative Commons license, and indicate if changes were made. 


\section{References}

Agarwal, B. (2012). Food security, productivity, and gender inequality. IEG Working Paper No. 320. University of Manchester, UK.

Agriculture Extension. (2004). Cited in: HIV/AIDS in rural Tonga Culture' by V.C. Ncube (2015); PhD thesis. Faculty of Theology, University of Pretoria, South Africa.

Anema, A., Vogenthaler, N., Frongillo, E. A., Kadiyala, S., \& Weiser, S. D. (2009). Food insecurity and HIV/AIDS: Current knowledge, gaps, and research priorities. Current HIV/AIDS Reports, 6, 224-231.

Basilwizi Trust. (2012). Zambezi valley child protection care and support baseline survey. Bulawayo: Basilwizi Trust.

Brody, A. (2015). Gender and food security: An overview. Bridge Development - Gender; In Brief. Institute of Development Studies (IDS) UK.

Corbin, J., \& Strauss, A. (2008). Basics of Qualitative research (3rd edition): Techniques and procedures for developing grounded theory. Thousand Oaks, CA: SAGE.

Cumanzala, R., \& Muleya, A. (2010) Zubo Gender Baseline Study (Unpublished) Cited in; FAWE: Forum for African Women Educationalists. FAWE Research Series, Vol. 3, 2013.

Currey, J. (2009). Crossing the Zambezi: The politics of landscape on a Central African Frontier. Avondale, Harare: Weaver Press.

De Wit, J. B. F., \& Adam, P. C. G. (2008). To test or not to test: Psychological barriers to HIV testing in high income countries. HIV Medicine, 9(Supplement S2), 20-22.

FAO. (2011). The state of food and agriculture-Women in agriculture: Closing the gender gap for development. Rome: FAO.

FAO, Ifad, UNICEF, WFP, \& WHO. (2018). The state of food security and nutrition in the world 2018: Building climate resilience for food security and nutrition. Rome: FAO.

FAO, Ifad, \& WFP. (2014). The state of food insecurity in the world: Strengthening the enabling environment for food security and nutrition. Rome: FAO.

Fawole, W. O., Ilbasmis, E., \& Ozkan, B. (2015) Food insecurity in Africa in terms of causes, effects and solutions: A case study of Nigeria. In 2nd International conference on sustainable agriculture and environment (Turkey) ResearchGate.

Frimpong, P. (2013). Food insecurity in Africa: Can we feed the world? http://www.modernghana.com/ news/444630/food-insecurity-in-africa-can-we-feed-the-world.

Haller, T., \& Merten, S. (2013). Losing the commons-Fighting with magic; Institutional change, fortress conservation and livelihood strategies of the Batwa, Kafue flats floodplain, Zambia. In L. Cliggett \& V. Bond (Eds.), Appraising sixty years of multidisplinary research in Zambia and Zimbabwe. Lusaka: Lembabi Trust.

Haralambos, M., \& Holborn, M. (2008). Sociology, themes and perspectives (7th ed.). London: Harper Collins.

Hyder, A. A., Maman, S., Nyoni, J. E., Khasiani, S. A., Teoh, N., Premji, Z., et al. (2005). The pervasive triad of food security, gender inequity and women's health: Exploratory research from sub-Saharan Africa. African Health Sciences, 5(4), 328-334.

Jackson, C. (2002). Rescuing gender from the poverty trap. World Development, 24(3), 489-504.

Jurgensen, M., Tuba, M., Fleykesnes, K., \& Blystad, A. (2012). The burden of knowing: Balancing benefits and barriers in HIV testing decisions: A qualitative study from Zambia. British Medical Council Health Services Research, 12(2), 1-11.

Kadiyala, S., \& Rawat, R. (2013). Food access and diet quality independently predict nutritional status among people living with HIV in Uganda. Public Health Nutrition, 16(1), 164-170.

Malungo, J. (2010). Marriage customs, patterns and practices, and sexual networks among the Tonga of Southern province, Zambia in the era of HIV and AIDS. In L. Cliggett \& V. Bond (Eds.), Tonga timeline: Appraising sixty years of multidisplinary research in Zambia and Zimbabwe. Lusaka: Lembani Trust.

Masa, R., \& Chowa, G. (2017). A multilevel conceptual framework to understand the role of food insecurity on antiretroviral therapy adherence in low-resource settings: From theory to practice. Social Work Public Health, 32(5), 324-338.

Mashingaidze, T. M. (2013). Beyond the Kariba Dam induced displacements: The Zimbabwean Tonga's struggles for restitution, 1990s-2000s. International Journal on Minority and Group Rights, 20, 381-404. 
Miller, C. L., Bangsberg, D. R., Tuller, D. M., Senkungu, J., et al. (2011). AIDS and Behaviour, 15(7), 1512-1519.

Muderedzi, J. T., Eide, A. H., Braathen, S. H., \& Stray-Pedersen, B. (2017). Exploring structural violence in the context of disability and poverty in Zimbabwe. African Journal of Disability, 6, a274. https://doi.org/10.4102/ajod.v610.274.

Muderedzi, J., Eide, A. H., Braathen, S. H., \& Stray-Pedersen, B. (2018). Vulnerable groups and structural violence. Case of the Tonga people of Binga in Zimbabwe: Coping of families with disabled children (Unpublished PHD thesis-University of Oslo).

Mudimba, V. M. (2015). The paradox of poverty in a paradise of plenty: A gender perspective on chronic poverty in Binga, Zimbabwe. Unpublished Master Thesis. The Hague: International Institute of Social Studies.

Munsaka, E. (2012). Including a disability agenda in development; Myth or reality? A case study of Binga District in Zimbabwe. Unpublished PhD thesis, Durham University.

Munsaka, E., \& Charnley, H. (2013). 'We do not have chiefs who are disabled': Disability, development and culture in a continuing complex emergency. Disability and Society, 28(6), 756-769.

Mwaramba and Associates. (2001). HIV/AIDS in rural Tonga culture by V. C. Ncube (2015). PhD thesis. Faculty of Theology, University of Pretoria, South Africa.

Ncube, V. (2016). HIV and AIDS in rural Tonga culture. Theological Studies, 72(1), 1-7.

O'Brien, R., Hunt, K., \& Hart, G. (2005). 'It's caveman stuff, but that is to a certain extent how guys still operate'; men's accounts of masculinity and help seeking. Social Science and Medicine, 61(2005), 503-516.

Rural Poverty in Zimbabwe; Rural Poverty Portal. (16-10-2015). www.ruralpovertyportal.org/count ry/home/tags/Zimbabwe.

Saunyama, J. (2017). Zimbabwe losing plot on food security due to women marginalization. NewsDay 15th February 2017. http://ruralwomenassembly.wordpress.com/2017 ...zim-losing-plot-on-foodsecurity/.

Sikwibele, A. L. (2010). Gender, culture, HIV and AIDS in contemporary Southern Zambia. In L. Cliggett \& V. Bond (Eds.), Tonga timeline: Appraising sixty years of multidisplinary research in Zambia and Zimbabwe. Lusaka: Lembani Trust.

Silverman, D. (2013). Doing qualitative research (4th ed.). London: SAGE.

Susser, I. (2009). AIDS, sex, and culture: Global politics and survival in Southern Africa. Malden, MA: Willey-Blackwell.

Tremmel, M., \& The River Tonga People. (1994). The people of the Great River. Gweru: Mambo Press.

Tsai, A. C., Bangsberg, D. R., Emenyonu, N., Senkungu, J. K., Martin, J. N., \& Weiser, S. D. (2011). The social context of food insecurity among persons living with HIV/AIDS in rural Uganda. Social Science Medicine, 73(12), 1717-1724.

UN DESA. (2015). (The United Nations Department of Economic and Social Affairs) The World's Women 2015: Trends and Statistics. New York.

Van Rooyen, H., McGrath, N., Chirowodza, A., Joseph, P., Fiamma, A., Gray, G., et al. (2013). Mobile VCT: Reaching men and young people in urban and rural South African Pilot Studies (NIMH Project Accept, HPTN 043). Aids and Behaviour, 17(9), 2946-2953.

Vogenthaler, N. S., Kushel, M. B., Hadley, C., Frongillo, E. D., Riley, D. R., Bangsberg, D. R., et al. (2013). Food insecurity and risky sexual behaviours among homeless and marginally housed HIV- infected individuals in San Francisco. AIDS and Behaviour, 17(5), 1688-1693. https://doi. org/10.1007/s10461-012-0355-2.

Weaver, L. J., \& Hadley, C. (2009). Moving beyond hunger and nutrition: A systematic review of the evidence linking food insecurity and mental health in developing countries. Ecology of Food and Nutrition, 48, 263-284.

Weiser, S. D., Palar, K., Hatcher, A. M., Young, S., Frongillo, E. A., \& Laraia, B. (2015). Food insecurity and health: A conceptual framework. Cited in: Food insecurity and public health: Ist edition (Editor-Louise Ivers). CRC Press.

Weiser, S. D., Tsai, A. C., Gupta, R., Frongillo, E. A., Tsai, A. C., et al. (2012). Food security is associated with morbidity and patterns of healthcare utilization among HIV-infected individuals in a resource poor setting. AIDS, 26(1), 67-75.

Weiser, S. D., Young, S. L., Cohen, C. R., Kushel, M. B., Tsai, A. C., Tien, P. C., et al. (2011). Conceptual framework for understanding the bidirectional links between food insecurity and HIV/ AIDS. American Journal Clinical Nutrition, 94, 1729S-1739S. 
ZCAWD. (2014). Zimbabwe country analysis working document final draft 3rd October 2014. Harare, Zimbabwe.

ZDHS. (2016). Zimbabwe Demographic and Health Survey. Calverton, MA: Zimbabwe National Statistics Agency and ICF International.

Zimbabwe National Population Census Report. (2012). Zimbabwe National Statistics Agency; Harare-Zimbabwe.

ZIMPHIA. (2016). Zimbabwe Population-Based HIV Impact Assessment. Harare: Ministry of Health and Child Care.

Publisher's Note Springer Nature remains neutral with regard to jurisdictional claims in published maps and institutional affiliations. 